\title{
The concerns of RAT Bucharest and ICPE SAERP Bucharest for environmental protection and reducing energy consumption in urban transportation
}

\author{
I. Străinescu ${ }^{1}$, V. Rădulescu ${ }^{1} \&$ P. Marin ${ }^{2}$ \\ ${ }^{I}$ ICPE SAERP S.A. Bucharest, Romania \\ ${ }^{2}$ RAT Bucharest, Romania
}

\begin{abstract}
The Public Transport Company from Bucharest, RATB, and the company ICPE SAERP are working side by side to ensure public transport in Bucharest by an electrical means of transportation. This is realized by improving the electrical vehicles (trams and trolleys) and by synchronization of the operation of RATB and METROREX. To ensure this kind of transportation in Bucharest and its surroundings, RATB uses a network of over $300 \mathrm{~km}$ of tramcar lines with a park of almost 500 tramcars, 18 trolley bus lines with a park of 300 trolley buses and an autobus park of 1300. The transportation lines in Bucharest depend on the 3 subway lines so that the transportation is optimum. The trolley bus park ensures civilized transportation with a negligible pollution level. In this case the exploitation costs are higher than for autobus transportation, but lower than for tramcar wagon transportation, and this is why it is easier to implement in Bucharest.
\end{abstract}

Keywords: urban transport management, trolleybus, tram.

\section{Introduction}

In the European Recommendation COM (2007) 551 final [1, page 3], we find the following:

- In the European Union, over $60 \%$ of the population lives in urban areas. Just less than $85 \%$ of the EU's gross domestic product - GDP - is 
created in urban areas. Towns and cities are the drivers of the European economy.

- Urban areas now constitute the living environment of the majority of the population, and it is imperative that the quality of life in these areas should be as high as possible.

- Throughout Europe, increased traffic in town and city centers has resulted in chronic congestion, with the many adverse consequences that this entails in terms of delay and pollution. Every year nearly 100 billion euros, or $1 \%$ of the EU's GDP, are lost to the European economy as a result of this phenomenon.

- Air and noise pollution is getting worse year by year. Urban traffic is responsible for $40 \%$ of $\mathrm{CO}_{2}$ emissions and $70 \%$ of emission of other pollutants arising from transport.

- The number of road traffic accidents in towns and cities is also growing each year: one in three fatal accidents now happen in urban areas and it is the most vulnerable people, namely pedestrian and cyclist, who are the main victims.

- Local authorities cannot face all this on their own; there is a need for cooperation and coordination at European level.

The main task of RATB is to ensure with Metrorex Bucharest (the public transportation society subordinate in the Transportation Ministry that assures subway transportation in Bucharest) passenger transportation in Bucharest and the surroundings of the city. This desideratum is especially hard to fulfill in the morning between 7 and 9, when the traffic reaches rush hour. On an average 2.514 .637 are personal transports, of which $84 \%$ of the destinations are in the administrative area of Bucharest and 16\% are transports between locations in Bucharest and surroundings.

To ensure this kind of transportation in Bucharest and surroundings, RATB uses a network of over $300 \mathrm{~km}$ tramcar lines with a park of almost 500 tramcars, 18 trolley bus lines with a park of 300 trolley buses and an autobus park of 1300 . The transportation lines in Bucharest depend on the 3 subway lines so that the transportation is optimum.

From the point of view of assuring the optimum passenger transportation in Bucharest, especially in the morning and in the evening, the autobus transportation would be optimum, because the defective autobuses would disturb in a small measure the urban traffic.

From the point of view of environment protection, this solution would be a catastrophe because Bucharest is already saturated with personal automobiles and taxies.

Today the gases produced by automobiles and some autobuses pollute Bucharest intensely and this happens also due to the few regulations in our country that allow cars and buses which emanate large quantities of polluting emissions well over the level allowed in Western Europe.

The RATB leadership board oriented in this direction, toward purchasing high performance autobuses, that will ensure an optimum transportation regarding comfort of passengers, low fuel consumption, acceptable pollution and 
high exploitation endurance. To support this, we have to observe that 1000 EVOBUS (Mercedes) autobuses with completely lowered floor have been purchased and run the whole network. As a trend, it is followed that the autobus transportation share is to be reduced, by expanding the urban electric transportation with tramcars, trolley buses and light-subway, driven by choppers and continuous current motors, respectively with inverters and three-phased asynchronous motors, that ensure large energy savings in traction regime and respectively electrical breaking with energy recovery which is transferred to the contact line and used by other vehicles in traction regime, connected to the contact line.

Beginning in the autumn of 2007, bicycle routes have been mapped out, conclusions being expected after using them for at least 6 months of springsummer 2008. Besides these marked bicycle routes, it is necessary that the infrastructure be completed by bicycle parking stands, specialized traffic lights, traffic signals with reflective paint and other specific means, including promotion in schools, universities, through mass-media and other means of information.

\section{Major measures needed for the protection of the environment}

From the environmental point of view it's obvious that the urban transportation has to be based on subway frames transport lines, special tramcar lines (lightsubway) - that will ensure free run for the tramcars (with automated barriers that will interrupt the run of other vehicles when the tramcar passes), ordinary tramcar and trolley bus lines, suspended electrical vehicles, dynamic electrical sidewalks and so on.

Various cities and metropolises try to resolve the issue of making urban transportation more efficient, with a lower pollution level. Cities that can ensure efficient a non-polluting public transportation, indirectly assure the reduction of pollution from the automobiles, because of the share reduction from public transportation assurance.

We have to notice that subway transportation assures a commercial speed of 30 to $45 \mathrm{~km} / \mathrm{hour}$, with run traffic of 90 seconds between two trains, a maximum load of 2000 passenger per train and distances between stations of 600 to 1000 meters. There are 3 subway lines in Bucharest and the fourth is in construction, but unfortunately the expansion of the subway lines has been diminishing for the last 17 years. The RATB leadership board applied the strategy of connecting the traffic to the subway lines so it can take over the passengers from the nearby subway stations. Today a common use of taxing systems has been developed, with contact less cards, transportation subscriptions for RATB's vehicle park (tramcars, trolley buses and autobuses) and subway, administrated by METROREX.

In case the transportation line with subway frames network will be subordinate to the Bucharest City Hall, like in Western Europe, an optimized and 
efficient transportation in Bucharest may be possible with a lower pollution level.

Regarding the transportation on special tramcar lines (light-subway), this could be carried out only in Bucharest's new districts. A serious investment is needed for constructing new tramcar lines and respectively rearranging existing line by completing them with automated barriers systems. In addition to that more tramcars must be purchased, that have a bigger transportation capacity, these being eligible of being driven by choppers and c.c. traction motors or respectively with three-phased inverters with IGBT transistors and three-phased asynchronous traction motors. In both situations the command will come from the active post along the train, as it was experimented on the Timisoara tramcar with VTC by ICPE SAERP Bucharest.

In Bucharest, the first modernized tramcar lines have been carried out and can be assimilated as light-subway lines - lines 41,32,35 with a length of over 200 $\mathrm{km}$, using articulated tramcar wagons or two coupled motor tramcar wagons, all of them using classic traction diagrams with electrical traction resistors and electrical breaking, so they have a lower average transport efficiency.

The RATB leadership board wants to carry out in the future the tramcar wagon trains transportation to neighboring localities and respectively the Bucharest City Hall recently approved some studies for the construction of a subway line from the Aurel Vlaicu subway station to the Henry Coanda International Airport, $18 \mathrm{~km}$ away.

We can say that the light-subway could assure in Bucharest a commercial speed of 25 to $30 \mathrm{~km} /$ hour, a traffic of 3 minutes distance between trains, a load of maximum 400 passengers (for a 2 tramcars train) and a distance of 450 to 700 meters between stations.

The tramcar park that assures passenger transportation on lines of almost 300 $\mathrm{km}$ (simple route) is efficient, assuring a safe and non-polluting transportation, even in the rush hour traffic. In this domain we want to keep the lines in good conditions, for the most part they now produce a reduced noise pollution, by integrating rubber dampers. We want to continue using the elastic wheels with rubber dampers. It is true that the ever-growing tramcar park assures an acceptable transportation in Bucharest with a much reduced pollution level than the autobus transportation, even if the exploitation costs are higher. A tramcar ensures the transportation of 200 passengers, at a commercial speed of 16 to 24 $\mathrm{km} /$ hour and a distance of 400 to 600 meters between stations.

Today almost all the tramcars used by RATB use classical electric driving diagrams with resistors, with a low efficiency, but in the next 2 to 4 years they wants to produce new tramcars equipped with choppers and c.c. traction motors and respectively three-phased invertors and asynchronous traction motors, in the future synchronous traction motors that will be delivered by ICPE SAERP Bucharest. In 2008, 18 tramcars will be delivered. The Bucharest City Hall approved funds for purchasing 100 modern, with low energy consumption and better passenger comfort tramcars, by international auction.

The trolley bus park ensures a civilized transportation with a negligible pollution level. In this case the exploitation costs are higher the autobus 
transportation, but lower than the tramcar wagon transportation, and this is why it's easier to implement in Bucharest.

On the 28 trolley bus lines, with a park of 300 modern trolley buses, driven by choppers and c.c. traction motors, RATB assures massive passenger transportation with low pollution level and great energy savings.

Together with the RATB specialists, between 1995 and 1996, 22 SAURER trolley buses have been developed, by transforming autobuses into chopper driven trolley buses. Most of them still run.

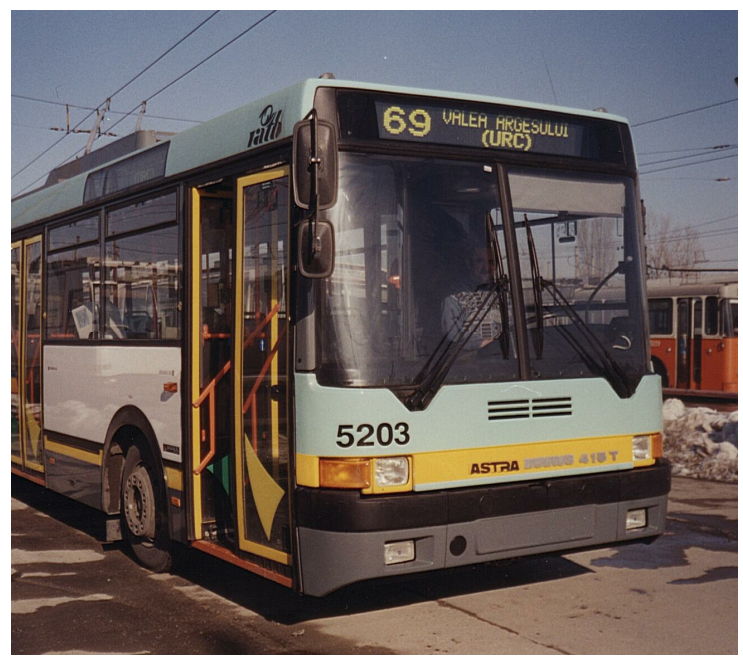

Figure 1: $\quad$ ASTRAIK 415T trolleybus for RATB.

Between 1997 and 2001, 203 ASTRA-IK 415T trolley buses have been produced by Astrabus Arad, which are equipped with choppers and respond very well in exploitation, fig 1.

Twenty- seven lowered floored, chopper and c.c. motor driven trolley buses have been delivered during 2001..2005 to Cluj, fig.2. Four chopper driving equipment have been mounted on Bulgarian bodywork and delivered to Sofia, Bulgaria.

Between 2006 and 2008, 100 lowered floor, chopper driven and c.c. motor trolley buses have been delivered to RATB, this way assuring one of EU's demands that recommends through one of its Directives that for every 3 vehicles at least 1 is equipped for people with disabilities, fig. 3 .

These trolley buses have performances in comfort, reliability and dynamics, having low specific energy consumption, equipped with choppers that have GTO thyristors for the first 100 trolley buses and IGBT transistors, fig, 4, for the last trolley buses delivered by ICPE SAERP.

The command, control and diagnosis blocks, fig.4, are developed using microprocessors, also delivered by ICPE SAERP.

The command system type SATREC - MMA with microprocessor developed by ICPE SAERP has the following functions: 


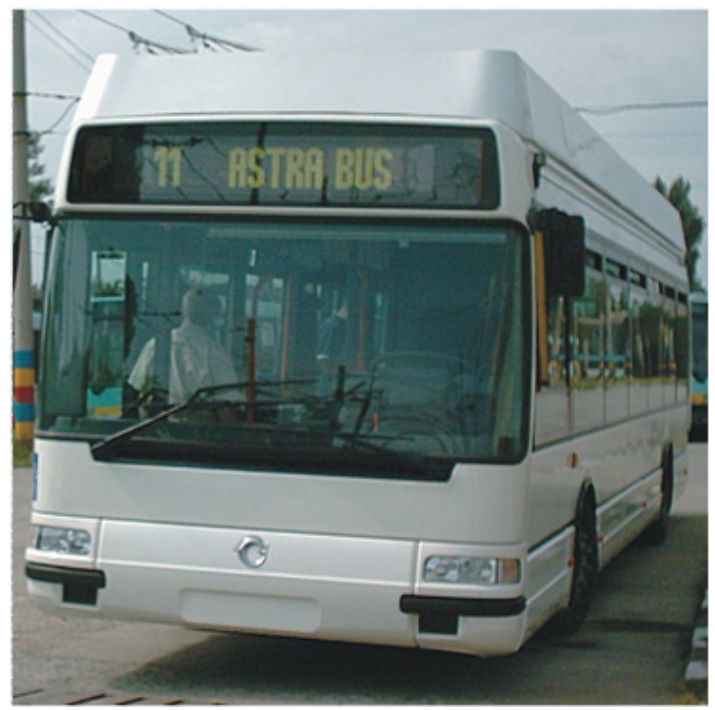

Figure 2: $\quad$ IRISBUS AGORA for Cluj-Napoca.

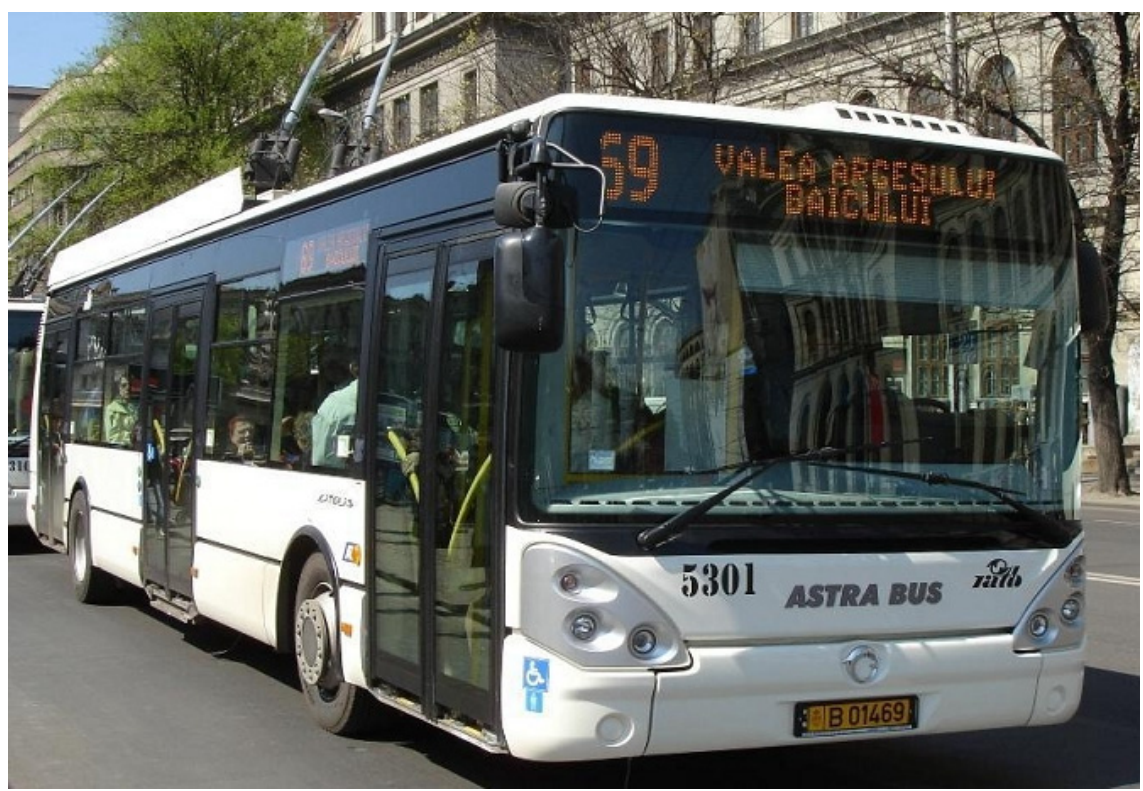

Figure 3: ASTRABUS CITELIS in Bucharest.

- Carries out the digital traction command.

- Carries out the command and control of all the assembly of the trolley bus's system (switches, contactors, door control, station breaking, ventilation). 
- The system's diagnosis and auto diagnosis, that transmit up to 128 events in real time to the driver's display and by connecting to a laptop computer, the last 1000 events may be downloaded.

- Parameters acquisition and displaying them on board (energy consumption, including the one recovered, kilometers, functioning hours, revision parameters).

- The command block has a digital microcontroller with a master microprocessor and many slave microprocessors, this way the command is done by programming entirely, and the integral circuits are being used only to convert the analogical input and output signals, gaining performance in command block's reliability and vehicles performance, including passenger comfort.

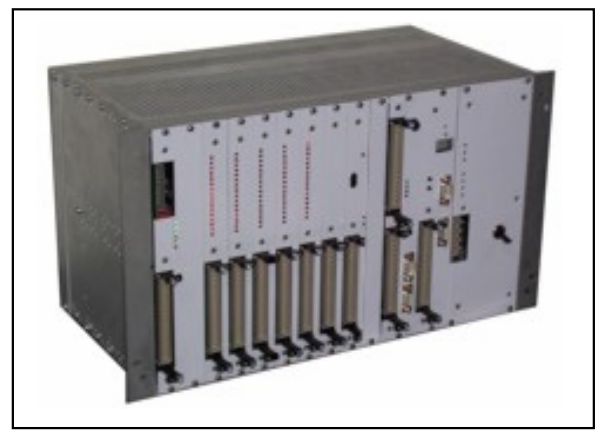

Figure 4: $\quad$ SATREC MMA control unit.

\section{Measures for reducing energy consumption and maintenance costs}

The measures regarding the trolley bus park were the purchase of new trolley buses that will run on a lower specific energy consumption and respectively modernizing the park, especially in replacing the generators for the auxiliary services with static converters, but also replacing the classical driving equipment with the one with choppers.

The electrical diagram with chopper has been patented and it ensures the following traction regimes: forward, backward, electrical breaking with energy recovery and rheostat electrical breaking, opposed to the demanded breaking, in cases in which the network can't receive the entire breaking energy. The energy savings belong to the 40 to $50 \%$ scale, in addition to supplementary maintenance savings of 15 to $25 \%$ an availability rise of the RATB park from 78 to $92 \%$.

\subsection{Converters for auxiliary services supplied from the network}

Command supply and storage batteries charging (24Vdc or110Vdc) for auxiliary services on tramcars

The supply sources produced by ICPE SAERP convert the energy from the high voltage of the supply network through a galvanic isolation plan, to the 
bumper battery voltage. The conversion is done with a resonant inverter, developed in the last few years at a frequency of more than $10 \mathrm{kHz}$, resulting in small gauges, fig.6. Over 600 static sources have been delivered nationwide.

Output voltage adjustment wants to:

- Limit the storage battery's charge current and bumper voltage control;

- Limit the total current rate;

- Voltage adjustment precision: $+/-2 \%$;

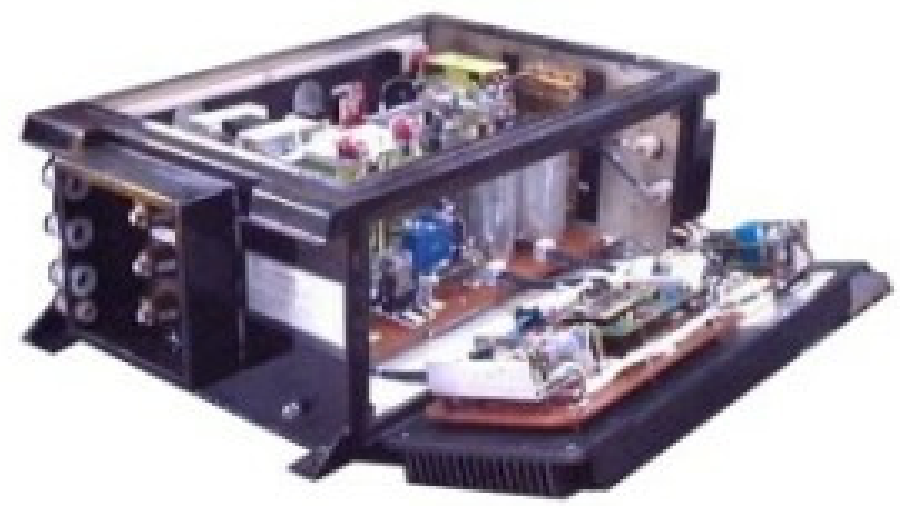

Figure 5: $\quad$ Static converter SIF 28 for tram.

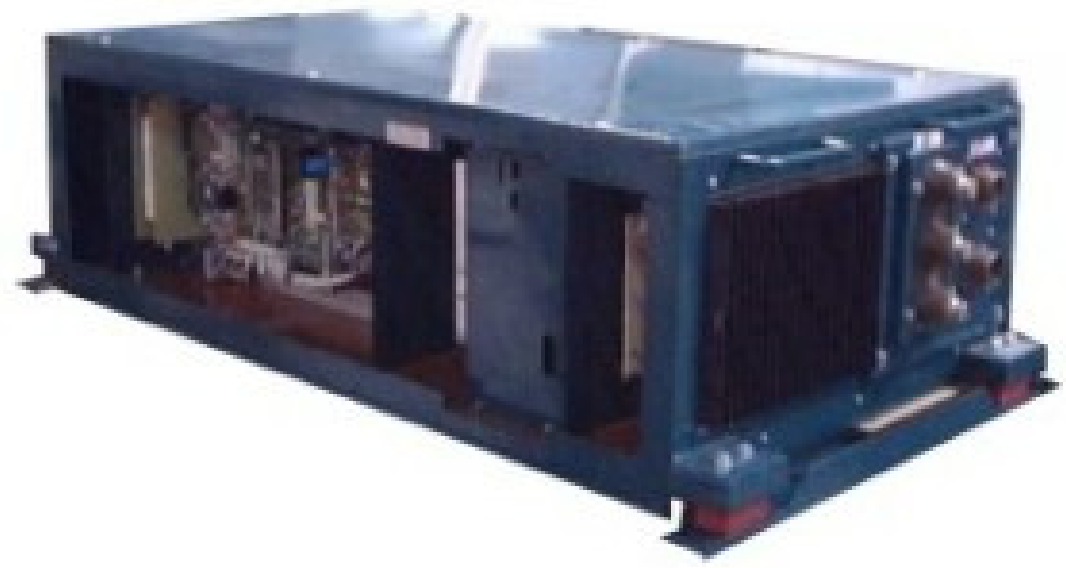

Figure 6: Static converter for trolley bus CS11T. 


\subsubsection{Auxiliary converters for trolley buses}

These have generally two output circuits, both double galvanic isolated from the supply voltage, fig. 7 .

- $28 \mathrm{Vcc}$ - for command supply and battery charging;

- 3x400Vca - for asynchronous motor supply for auxiliary services (compressor, servo-direction, fans).

\subsubsection{The three-phased output is usually characterized by:}

- Fixed frequency in stationary regime;

- At start-up, phase voltage and frequency evolve linear, with a constant ratio, for the slow starting asynchronous motors;

- Supply voltage variation compensation;

- The current and output voltages are sinusoidal, with a maximum of $8 \%$ harmonics;

- Overload, short circuit and overheating protection.

Over 350 sources have been delivered.

\section{Conclusions}

From the analysis done by various authorities in Europe, Japan and the USA we reached the conclusion that the pollution in the big cities may be reduced if an well organized urban transportation can be secured, with modern means of transportation, especially those that use underground and surface subway networks (on special routes, including light-subway), completed by connection lines that use tramcars, trolley buses and hybrid fuel cell based electrical autobuses that are parallel connected with modern electrical storage batteries. A strong urban transportation network reduces substantially the number of automobiles and so the pollution can be diminished as can be observed in some cities in Great Britain, Netherlands, France, Germany and Denmark. In addition to this, through a well organized urban electric transportation, we can assure an optimum run of passengers from the big cities, with an acceptable comfort and drastic limitation of pedestrian and bicycle related accidents.

All of this implies large investments distributed over long time periods and respective subsidies from the city halls that should cover the exploitation costs after renouncing of most of the diesel autobuses and powerful expansion of nonpolluting electrical transportation.

This is well covered in the European Recommendation COM (2007) 551 final [1, page 1, 9, 19,20]:

- Local authorities cannot face all these issues on their own: there is need for cooperation and coordination at European level. The vital issue of urban mobility needs to be addressed as part of collective effort at levels: local, regional, national and European. The European Union must play a leading role in order to focus attention on this issue.

- Extension, rehabilitation and upgrading of clean urban public transport such as trolley buses, trams, metros and suburban rail as well as other 
sustainable urban transport projects should continue to be promoted and supported by the UE.

- According to a recent study, over $40 \%$ of the urban tram and light rail fleet in the EU-15 and $67 \%$ of the fleet in the new Member States is over 20 years old and ought to be replaced before 2020 .

- At EU level several sources of financing are available, for instance the Structural Funds, the Cohesion Fund and loans from the European investment Bank. As in the past, the EU's Cohesion Policy will remain an important source of funds in the eligible region during the period 2007-2013.

- According to the programming documents, European Regional Development Fund - ERDF - and Cohesion Fund will contribute to almost $€ 8$ billion for urban transport during the 2007-2013 period.

- The cohesion instruments in the current period 2007-2013 provide a more broad and solid basis for co-financing urban transport and collective transport across Europe. The ERDF and Cohesion Fund regulations make explicit reference to clean urban transport and public transport but also, for he first time, to integrated strategies for the clean transport.

As it results from the current essay, RATB together with ICPE SAERP tried to and are still trying to modernize the urban transportation in Bucharest, so that they can secure a civilized transportation, without leaving aside the issue of pollution reduction in Bucharest [2].

Three light-subway lines have been constructed, in order not to be disturbed by automobiles, trucks and heavy vehicles. In this domain we have to use modern driving with choppers and c.c. traction motors and respectively threephased inverters and asynchronous three-phased traction motors and/or synchronous, with high exploitation efficiency and low maintenance costs.

The tramcar park must be modernized fast and it's necessary to create 3 to 5 new tramcar lines and 2 new subway lines, in which action ICPE SAERP Bucharest will especially be involved.

A great investment has been made in the trolley bus park that uses for the most part modern trolley buses and which will expand with trolley buses that are driven by three-phased inverters and asynchronous and synchronous threephased traction motors. In this action as well, ICPE SAERP Bucharest has been and probably will be involved.

For a stronger development of the electrical non-polluting vehicle park, the support of the Bucharest City hall will be needed, but also the Structural Funds from the EU and Frame VII Research Funds. We're interested in forming strong collectives from a number of European countries to ensure the urban transportation modernization in the big cities in Europe, especially in Eastern Europe.

According to the MASTER PLAN PMB, elaborated by the Bucharest City hall for the 2008-2027 period, it is to be followed that the capacity of the road transportation network will increase. 
The improvement of the public transportation will be done not only by introducing new routes/lines, but also by improving the performances of existing networks and also by implementing intelligent traffic management systems.

Unfortunately in many cities in Romania, especially in Constanta and Brasov, the protection of the environment is completely neglected by the authorities, which decided to suppress some tramcar and trolley bus lines in order to replace them with bad quality and heavy polluting autobuses. We hope that following the proposals of the EU, the Romanian Government and the city halls will be interested in the future in non-polluting urban transportation.

\section{References}

[1] Green Paper. Towards a new culture for urban mobility. Commission of the European Communities. Brussels, 25.9. 2007- COM (2007) 551 FINAL.

[2] Master Plan for Urban Transport in Bucharest. 15.04.2008, General Counsil of Bucharest. 